\title{
PENERAPAN PROFILE MATCHING UNTUK SELEKSI ASISTEN LABORATORIUM
}

\author{
Sri Rahayu Astari(1), Rusydi Umar(2), Sunardi(3) \\ ${ }^{1}$ Teknik Informatika, Fakultas Teknik Industri UPN “Veteran" Yogyakarta \\ 1,2Magister Teknik Informatika, Universitas Ahmad Dahlan \\ ${ }^{3}$ Teknik Elektro, Universitas Ahmad Dahlan \\ e-mail : tarisrtari@gmail.com ${ }^{(1)}$
}

\begin{abstract}
Laboratory assistants in universities are usually active students who are recruited to help lecturers implement theoretical courses given by lecturers in class. Assistant recruitment is carried out to screen students who have talent in teaching, because in addition to assisting lecturers in providing practical material, becoming an assistant is a way to measure personal abilities that have talent in teaching. This study applies the profile matching method by determining the gap value which is the difference between the candidate values and the standard that has been set between the profile data from the selected assistant candidates. The purpose of applying this profile matching method is to get an assistant that is in accordance with the main and supporting factors that the reviewer will determine in each selection. Calculation using the profile matching method gives different weights to each criterion, so that the criteria have weights according to the type or standard of interest. This study uses a prototype method that involves the user in the analysis process. This study resulted in a calculation method using the profile matching method by determining each criterion weight, then classifying or dividing criteria into core factors and secondary factors which ultimately resulted in the total amount of the whole, and then ranking.
\end{abstract}

\section{Keywords : Assistant, Profile Matching, decision making, core factors, secondary factors.}

Asisten laboratorium di perguruan tinggi biasanya merupakan mahasiswa aktif yang direkrut untuk membantu dosen mengimplementasikan mata kuliah teori yang diberikan dosen dikelas. Rekrutmen asisten dilakukan untuk menyaring mahasiswa yang memiliki bakat dalam mengajar, karena selain untuk membantu dosen dalam memberikan materi praktikum, menjadi asisten adalah cara untuk mengukur kemampuan personal yang memiliki bakat dalam mengajar. Penelitian ini menerapkan metode profile matching dengan menentukan nilai gap yang merupakan selisih nilai calon dengan standar yang sudah ditetapkan antara profil data dari calon asisten yang diseleksi. Tujuan dari penerapan metode profile matching ini adalah untuk mendapatkan asisten yang sesuai dengan faktor utama dan pendukung yang akan ditentukan reviewer setiap seleksi dilakukan. Perhitungan menggunakan metode profile matching memberikan bobot berbeda pada setiap kriteria, agar kriteria mempunyai bobot sesuai dengan tipe atau standar kepentingannya. Penelitian ini menggunakan metode prototype yang melibatkan user dalam proses analisis. Penelitian ini menghasilkan cara perhitungan menggunakan metode profile matching dengan menentukan setiap bobot kriteria, kemudian mengelompokkan atau membagi kriteria menjadi core factor dan secondary factor yang akhirnya menghasilkan jumlah total dari keseluruhan, dan kemudian dilakukan perankingan.

Kata Kunci : Asisten, Profile Matching, pengambilan keputusan, core factor, secondary factor.

\section{PENDAHULUAN}

Asisten laboratorium sering dijumpai ketika mahasiswa melakukan praktikum. Di perguruan tinggi asisten laboratorium merupakan mahasiswa aktif. Praktikum merupakan metode untuk mengimplementasikan teori berdasar output akhir dari mata kuliah yang bersangkutan. Untuk menjadi asisten laboratorium tentu tidak mudah, ada beberapa syarat dan kriteria yang harus dipenuhi calon asisten agar terpilih menjadi seorang asisten. Bukan hanya pintar dan mempunyai nilai yang baik tapi beberapa kriteria seperti cara menyampaikan materi yang baikpun harus dikuasai oleh calon asisten. 
Di Jurusan Teknik Informatika UPN "Veteran" Yogyakarta ketika melakukan seleksi asisten laboratorium ditentukan terlebih dahulu kriteria dan aspek yang sesuai dengan kebutuhan praktikum. Masalah yang sering dialami oleh tim seleksi ketika melakukan penilaian potensi calon asisten adalah pengambilan keputusan. Jika beberapa calon asisten memiliki kemampuan yang hampir sama, maka tim seleksi perlu waktu lagi untuk mempertimbangkan nilai yang akan diberikan, tentunya tim seleksi berharap untuk mengambil keputusan yang terbaik untuk mendapatkan kualitas asisten yang baik. Seleksi asisten terdiri dari aspek-aspek tertentu yang diberikan nilai sesuai dengan kemampuan calon asisten. Aspek tersebut dinilai dari tes administrasi, tes kompetensi, tes microteaching dan tes wawancara. Hampir semua tes dilakukan secara manual dan setiap kriteria tidak pernah ditentukan bobotnya, sehingga semua kriteria terkesan sama penting dan memiliki standar nilai yang sama.

Menurut Rusydi et al (2018), Sistem Pendukung Keputusan yaitu sistem yang dapat membantu memecahkan masalah, melakukan komunikasi dalam memecahkan masalah dengan terstruktur ataupun tidak terstruktur. Untuk membantu tim seleksi terhadap permasalahan yang sudah dijelaskan maka diterapkan metode profile matching dalam melakukan perhitungan pengambilalan keputusan, setiap aspek yang ditentukan memiliki tipe yang membantu mempertimbangkan nilai akhir. Tipe pada kriteria yang akan diterapkan adalah core factor dan secondary factor. Dengan menggunakan metode profile matching maka setiap kriteria memiliki nilai standar yang ditetapkan koordinator laboratorium, sehingga kriteria yang akan digunakan terlihat tingkat kepentingannya berdasarkan tipenya.

\section{TINJAUAN PUSTAKA}

Pada penelitian yang dilakukan Bety, W.S (2015), dikutip dari McLeod Jr, Raymond. (1998) bahwa Sistem pendukung keputusan merupakan sistem yang dapat membantu dalam menyelesaikan masalah dan komunikasi yang bersifat semi-terstruktur. Penelitian Bety berjudul Perbandingan Metode Profile Matching dan Simple Additive Weighting Pada Penentuan Jurusan Siswa Kelas X Sma N 2 Ngaglik. Menurut Kusrini (2007), profile matching atau pencocokan profil adalah metode yang sering digunakan sebagai mekanisme dalam pengambilan keputusan dengan mengasumsikan bahwa terdapat tingkat variabel prediktor yang ideal yang harus dipenuhi oleh subyek yang diteliti, bukannya tingkat minimal yang harus dipenuhi atau dilewati. Pada penelitiannya Bety mencoba membandingkan dengan metode Simple Additive Weighting yang hasil akhirnya menunjukkan hasil yang sama.

Andoko et al (2018) melakukan penelitian dengan judul Penerapan Metode Multi Factor Evaluation Process (MFEP) Pada Sistem Pendukung Keputusan Penentuan Kelayakan Pemberi Pinjaman (Studi Kasus NSC Finance Kota Lubuklinggau). Penelitian ini dibuat karena pimpinan NSC Finance dalam pengambilan keputusan tidak melakukan perhitungan dan mengakibatkan banyak konsumen yang menunggak. Pimpinan menyeleksi kelayakan peminjam dengan memeriksa berkas hardcopy satu per satu sehingga membuat pimpinan kesulitan mengambil keputusan. Menurut Henry Pratiwi (2014), MFEP adalah metode kuantitatif yang menggunakan "weighting system" dalam pengambilan keputusan multi faktor, pengambilan keputusan secara subjektif dan intuitif menimbang berbagai faktor yang mempunyai pengaruh penting terhadap alternatif pilihan mereka.

Pada Penelitian yang sedang dilakukan ini, yang menjadi objek adalah calon asisten laboratorium. Pada pemilihan calon asisten terdapat kriteria-kriteria yang dibutuhkan oleh jurusan teknik informatika UPN untuk kebutuhan tenaga pengajar praktikum di laboratorium. Metode yang digunakan adalah profile matching, terdapat kriteria core factor dan secondary factor yang membantu dalam pengambilan keputusan berdasarkan besar bobot yang dimiliki. Hasil dari penelitian ini berupa ranking dengan nilai terbesar. Asisten yang terpilih adalah sesuai standar kriteria yang sudah ditentukan oleh ketua laboratorium. 


\section{METODE PENELITIAN}

\subsection{Pengembangan Sistem}

Dalam pengembangan sistem pada penelitian ini menggunakan metode prototype. Perangkat lunak yang dihasilkan ditunjukkan kepada pelanggan, yang akan memberikan saran ataupun masukan untuk memperbaiki perancangan jika belum sesuai dengan yang dibutuhkan. Perancangan ulang untuk memperbaiki rancangan yang sebelumnya untuk menghasilkan sistem yang benar-benar sesuai dengan kebutuhan (A Fadlil et al, 2016). Menurut Nurajizah (2015) langkah-langkah dalam pengembangan sistem menggunakan prototype seperti pada Gambar 1.

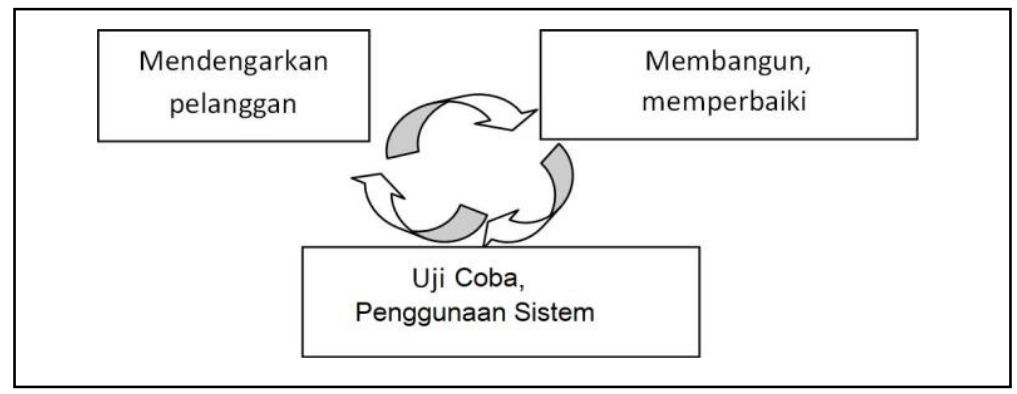

Gambar 1. Langkah-langkah prototype

1. Analisis kebutuhan

Tahapan pertama dilakukan untuk mengidentifikasi kebutuhan sistem yang akan dibangun.

2. Membangun prototype

Tahap kedua, membangun perancangan sesuai dengan yang sudah dilakukan di tahap pertama.

3. Evaluasi

Tahap ketiga, pelanggan mengevaluasi perancangan yang sudah dibuat, untuk memastikan bahwa perancangan yang sudah dibuat sudah sesuai atau belum dengan kebutuhan pelanggan. Jika sudah maka akan dilakukan pengkodean hingga aplikasi sesuai dengan yang dibutuhkan.

4. Penggunaan sistem

Terakhir adalah tahap penggunaan sistem dimana setelah pengujian dan evaluasi tidak ada yang perlu diperbaiki lagi. Sistem sudah bisa digunakan oleh pelanggan.

\subsection{Metode Profile Matching}

Penelitian ini menggunakan metode profile matching. Menurut Andri, A.T.S (2017), Konsep metode profile matching adalah membandingkan antara kompetensi individu dengan kompetensi yang harus dimiliki oleh calon asisten. Diketehui perbedaan kompetensi atau gap nya. Semakin kecil gap yang dihasilkan maka semakin besar peluang untuk menjadi asisten. Nilai gap yang akan digunakan terdapat pada Tabel 1.

Tabel 1. Bobot nilai GAP

\begin{tabular}{|c|c|l|}
\hline Selisih & Bobot Nilai & \multicolumn{1}{c|}{ Keterangan } \\
\hline 0 & $\mathbf{5}$ & Tidak ada selisih (Kompetensi sesuai dengan kebutuhan) \\
\hline 1 & $\mathbf{4 , 5}$ & Kompetensi individu kelebihan 1 tingkat \\
\hline-1 & $\mathbf{4}$ & Kompetensi individu kekurangan 1 tingkat \\
\hline 2 & $\mathbf{3 , 5}$ & Kompetensi individu kelebihan 2 tingkat \\
\hline-2 & $\mathbf{3}$ & Kompetensi individu kekurangan 2 tingkat \\
\hline 3 & $\mathbf{2 , 5}$ & Kompetensi individu kelebihan 3 tingkat \\
\hline-3 & $\mathbf{2}$ & Kompetensi individu kekurangan 3 tingkat \\
\hline 4 & $\mathbf{1 , 5}$ & Kompetensi individu kelebihan 4 tingkat \\
\hline-4 & $\mathbf{1}$ & Kompetensi subjek kekurangan 4 tingkat / level \\
\hline
\end{tabular}


Tahapan dari perhitungan menggunakan metode Profile Matching yaitu :

1. Menentukan aspek dan kriteria yang digunakan untuk penilaian calon asisten. Aspek dan kriteria ditentukan oleh kepala laboratorium.

2. Menentukan bobot dari masing-masing kriteria yang juga ditentukan oleh kepala laboratorium.

3. Menghitung perbandingan nilai gap.

Gap = Nilai Calon - Nilai Standar

4. Mengelompokan nilai core factor dan secondary factor.

a. Core factor merupakan tipe kriteria yang paling penting pada calon asisten yang harus dimiliki. Menghitung core factor dapat dicari dengan menggunakan rumus berikut :

$$
N C F=\frac{\sum N C}{\sum I C}
$$

Keterangan:

$\mathrm{NCF}=$ Nilai rata-rata Core Factor

$\mathrm{NC}=$ Jumlah Total nilai Core Factor (atribut 1, atribut 2, dst)

IC = Jumlah aspek Core Factor

b. Secondary factor merupakan kriteria pendukung atau selain dari kriteria utama. Secondaryf actor dapat dicari dengan persamaan 3 di bawah ini :

$$
N S F=\frac{\sum N S}{\sum I C}
$$

Keterangan:

NSF = Nilai rata-rata Secondary Factor

NC = Jumlah Total nilai Secondary Factor (atribut 1, atribut 2, dst)

IC = Jumlah aspek Secondary Factor

Penentuan tipe core factor dan secondary factor ditentukan oleh ketua laboratorium dengan mempertimbangkan kebutuhan calon asisten yang dibutuhkan.

5. Melakukan perankingan dimulai dari nilai paling besar ke nilai terkecil.

\section{HASIL DAN PEMBAHASAN}

Serangkaian tahap pengumpulan data dilakukan untuk menentukan aspek dan kriteria yang digunakan sebagai parameter dalam metode profile matching. Data aspek dan kriteria yang digunakan dalam penelitian terdapat pada Tabel 2. Setiap kriteria memiliki target atau standar yang sudah ditentukan oleh kepala laboratorium.

Tabel 2. Aspek dan Kriteria

\begin{tabular}{|c|l|c|l|}
\hline Aspek & \multicolumn{1}{|c|}{ Kriteria } & Target & \multicolumn{1}{c|}{ Tipe } \\
\hline \multirow{3}{*}{ Administrasi } & IPK & 5 & Core factor \\
\cline { 2 - 4 } & Algoritma dan Jaringan & 4 & Core Factor \\
\cline { 2 - 4 } & Sertifikasi & 3 & Secondary Factor \\
\hline \multirow{4}{*}{ Tes Kompetensi } & Pemrograman dan Jaringan & 4 & Core factor \\
\cline { 2 - 4 } & Suara & 4 & Core factor \\
\cline { 2 - 4 } & Penguasaan Materi & 3 & Secondary Factor \\
\cline { 2 - 4 } & Penyampaian Materi & 3 & Secondary Factor \\
\cline { 2 - 4 } & Sikap & 4 & Core factor \\
\cline { 2 - 4 } & Interaksi & 5 & Core factor \\
\hline \multirow{3}{*}{ Aspek } & \multicolumn{1}{|c|}{ Kriteria } & 3 & Target \\
\hline \multirow{3}{*}{ Wawancara } & Karakter & 5 & Cocondary Factor \\
\cline { 2 - 4 } & Komitmen & 5 & Core factor \\
\cline { 2 - 4 } & Konsistensi & & \\
\hline
\end{tabular}


Setiap target yang sudah ditentukan pada Tabel 2 memiliki arti seperti yang dijelaskan pada Tabel 3. Jika target pada Tabel 2 bernilai 5, maka bobot 5 memiliki nilai sangat penting.

Tabel 3. Bobot nilai kriteria

\begin{tabular}{|c|c|}
\hline Nilai & Bobot \\
\hline Sangat Penting & 5 \\
\hline Penting & 4 \\
\hline Cukup Penting & 3 \\
\hline Kurang Penting & 2 \\
\hline Tidak Penting & 1 \\
\hline
\end{tabular}

\section{A. Penilaian Aspek dan Kriteria}

Proses perhitungan menggunakan profile matching akan dijelaskan pada Tabel 4. Sampai dengan Tabel 11.

\section{Aspek Administrasi}

Pada tahap tes administrasi yang diseleksi dari calon asisten adalah besar IPK, nilai algoritma dan jaringan yang sudah didapatkan pada semester sebelumnya, kemudian kelebihan memiliki sertifikat keahlian.

Tabel 4. Administrasi

\begin{tabular}{|c|c|c|c|c|}
\hline KodeNama & IPK & Algoritma & Jaringan & Sertifikat \\
\hline R & 3,88 & B & A & Ada \\
\hline O & 3,88 & B & B & - \\
\hline J & 3,24 & A & B & Ada \\
\hline H & 3,68 & B & B & - \\
\hline TARGET & 3 & \multicolumn{2}{|c}{4} & 3 \\
\hline
\end{tabular}

Nilai kriteria yang dimiliki calon asisten akan dikonversikan kedalam bobot penilaian profile matching yang sudah disepakati, yaitu 1 sampai dengan 5. Nilai konversi IPK terdapat pada Tabel 5. Nilai algoritma dan jaringan di konversikan dengan nilai angka yang terdapat pada Tabel 6 , kemudian dicari nilai rata-rata dari kedua nilai tersebut sehingga menghasilkan NilaiKuliah. Sedangkan untuk sertifikat keahlian jika memiliki maka bernilai 3 dan jika tidak memiliki bernilai 1 .

Contoh : R memiliki nilai Algoritma B dan Jaringan A. Berdasarkan Tabel 6 maka B memiliki bobot 3,0 dan A 4,0. Sehingga untuk mencari rata-ratanya yaitu :

$(3,0+4,0) / 2=3,5$. Sehingga Nilai untuk NilaiKuliah adalah 4 , mengacu pada Tabel 5 bahwa bobot 3,5 bernilai 4 .

Tabel 5. Pembobotan Nilai IPK dan Nilai Kuliah

\begin{tabular}{|c|c|}
\hline Nilai & Bobot \\
\hline 5 & $3,51-4,00$ \\
\hline 4 & $3,01-3,50$ \\
\hline 3 & $2,51-3,00$ \\
\hline 2 & $1,01-2,50$ \\
\hline
\end{tabular}


Tabel 6. Konversi Nilai Huruf

\begin{tabular}{|c|c|}
\hline Nilai & Bobot \\
\hline A & 4,0 \\
\hline B+ & 3,5 \\
\hline B & 3,0 \\
\hline C+ & 2,5 \\
\hline C & 2,0 \\
\hline D & 1,5 \\
\hline E & 1,0 \\
\hline
\end{tabular}

Hasil dari pembobotan IPK, konversi nilai huruf dan sertifikat keahlian terdapat pada Tabel 7.

Tabel 7. Konversi Hasil Tes Administrasi

\begin{tabular}{|c|c|c|c|}
\hline KodeNama & IPK & NilaiKuliah & Sertifikat \\
\hline R & 5 & 4 & 3 \\
\hline O & 5 & 3 & 1 \\
\hline J & 4 & 4 & 3 \\
\hline H & 5 & 3 & 1 \\
\hline
\end{tabular}

2. Aspek Kompetensi

Dalam aspek ini dilakukan penilaian terhadap kemampuan pemrograman dan kemampuan jaringan calon asisten. Dicari rata-rata dari nilai kompetensi pemrograman dan jaringan yang terdapat pada kolom Rata-rata pada Tabel 8. Nilai pada kolom Hasil yang didapatkan kemudian dikonversikan sesuai dengan range nilai yang terdapat pada Tabel 9, sehingga hasil akhir dari tes kompetensi terdapat pada Tabel 10.

Tabel 8. Hasil Kompetensi

\begin{tabular}{|c|c|c|c|c|}
\hline KodeNama & Pemrograman & Jaringan & Rata-Rata & TARGET \\
\hline $\mathrm{R}$ & 85 & 60 & 72,50 & \multirow[t]{4}{*}{ 1.7. } \\
\hline 0 & 80 & 50 & 65,00 & \\
\hline $\mathrm{J}$ & 65 & 70 & 67,50 & \\
\hline $\mathrm{H}$ & 50 & 20 & 35,00 & \\
\hline
\end{tabular}

Tabel 9. Konversi Range Nilai

\begin{tabular}{|c|r|}
\hline Nilai & Prog+Jarkom \\
\hline 5 & $81-100$ \\
\hline 4 & $61-80$ \\
\hline 3 & $41-60$ \\
\hline 2 & $21-40$ \\
\hline 1 & $1-20$ \\
\hline
\end{tabular}

Tabel 10. Konversi hasil kompetensi

\begin{tabular}{|c|r|}
\hline KodeNama & Prog+Jarkom \\
\hline $\mathrm{R}$ & 4 \\
\hline $\mathrm{O}$ & 4 \\
\hline $\mathrm{J}$ & 4 \\
\hline $\mathrm{H}$ & 2 \\
\hline
\end{tabular}


3. Aspek Microteaching

Hal yang di nilai dalam aspek ini adalah Suara (1), Penguasaan Materi (2), Penyampaian Materi (3), Sikap (4) dan Interaksi (5). Penilaian dilakukan secara langsung mengacu pada Tabel 10. Hasil akhir dari penilaian terdapat pada Tabel 11.

Tabel 10. Bobot Penilaian

\begin{tabular}{|c|c|}
\hline Nilai & Bobot \\
\hline Sangat Baik & 5 \\
\hline Baik & 4 \\
\hline Cukup Baik & 3 \\
\hline Kurang Baik & 2 \\
\hline Tidak Baik & 1 \\
\hline
\end{tabular}

Tabel 11. Hasil Microteaching

\begin{tabular}{|c|r|r|r|r|r|}
\hline KodeNama & Suara & $\begin{array}{c}\text { Penguasaan } \\
\text { Materi }\end{array}$ & $\begin{array}{c}\text { Penyampaian } \\
\text { Materi }\end{array}$ & Sikap & Interaksi \\
\hline R & 5 & 3 & 4 & 5 & 4 \\
\hline O & 3 & 4 & 3 & 4 & 3 \\
\hline J & 4 & 3 & 3 & 4 & 4 \\
\hline H & 3 & 5 & 4 & 4 & 5 \\
\hline
\end{tabular}

\section{Aspek Wawancara}

Hal yang dinilai dalam aspek ini adalah Karakter (1), Komitmen (2) dan Konsisten (3). Penilaian tes wawancara dilakukan secara langsung dengan mengacu pada Tabel 10 , sehingga hasil akhir pada tes wawancara terdapat pada Tabel 12.

Tabel 12. Hasil Wawancara

\begin{tabular}{|c|r|r|r|}
\hline KodeNama & Karakter & Komitmen & Konsisten \\
\hline $\mathrm{R}$ & 4 & 4 & 4 \\
\hline $\mathrm{O}$ & 5 & 4 & 4 \\
\hline $\mathrm{J}$ & 3 & 3 & 3 \\
\hline $\mathrm{H}$ & 4 & 3 & 3 \\
\hline
\end{tabular}

\section{B. Pemetaan GAP}

Gap merupakan selisih nilai calon dengan standar yang sudah ditetapkan seperti pada Tabel 13 sampai dengan Tabel 16. Preferensi merupakan standar nilai yang harus dipenuhi, pada Tabel 13 sampai dengan Tabel 16, nilai profil calon asisten dituliskan sebelum preferensi, kemudian selisih nilai gap calon dituliskan setelah nilai preferensi yaitu bagian bawah tabel.

Tabel 13. GAP Administrasi

\begin{tabular}{|c|c|c|c|l|}
\hline KodeNama & IPK & Algo+jar & Sertifikasi & \\
\hline R & 5 & 4 & 3 & \\
\hline O & 5 & 3 & 1 & \multirow{2}{*}{ Profil } \\
\hline J & 4 & 4 & 3 & \\
\hline H & 5 & 3 & 1 & \\
\hline PREFERENSI & 5 & 4 & 3 & \\
\hline R & 5 & 5 & 5 & GAP \\
\hline
\end{tabular}




\begin{tabular}{|c|c|c|c|c|}
\hline KodeNama & IPK & Algo+jar & Sertifikasi & \\
\hline O & 3,5 & 4 & 3 & \\
\cline { 1 - 4 } $\mathrm{J}$ & 4,5 & 5 & 5 & \\
\hline $\mathrm{H}$ & 3,5 & 4 & 3 & \\
\hline
\end{tabular}

Tabel 14. GAP Kompetensi

\begin{tabular}{|c|c|c|}
\hline KodeNama & Prog+Jarkom & \\
\hline R & 4 & \\
\hline O & 4 & \multirow{3}{*}{ Profil } \\
\hline J & 4 & \\
\hline H & 2 & \\
\hline PREFERENSI & 4 & \\
\hline R & 5 & \\
\hline O & 5 & \multirow{3}{*}{ GAP } \\
\hline J & 5 & \multirow{2}{*}{} \\
\hline H & 3 & \\
\hline
\end{tabular}

Tabel 15. GAP Microteaching

\begin{tabular}{|c|c|c|c|c|c|c|}
\hline KodeNama & Suara & Penguasaan Materi & Penyampaian Materi & Sikap & Interaksi & \\
\hline $\mathrm{R}$ & 5 & 3 & 4 & 5 & 4 & \multirow{4}{*}{ Profil } \\
\hline $\mathrm{O}$ & 3 & 4 & 3 & 4 & 3 & \\
\hline$J$ & 4 & 3 & 3 & 4 & 4 & \\
\hline $\mathrm{H}$ & 3 & 5 & 4 & 4 & 5 & \\
\hline PREFERENSI & 4 & 3 & 3 & 4 & 5 & \\
\hline $\mathrm{R}$ & 4,5 & 5 & 4,5 & 4,5 & 4 & \multirow{4}{*}{ GAP } \\
\hline 0 & 4 & 4,5 & 5 & 5 & 3 & \\
\hline$J$ & 5 & 5 & 5 & 5 & 4 & \\
\hline $\mathrm{H}$ & 4 & 3,5 & 4,5 & 5 & 5 & \\
\hline
\end{tabular}

Tabel 16. GAP Wawancara

\begin{tabular}{|c|c|c|c|c|}
\hline KodeNama & Karakter & Komitmen & Konsisten & \\
\hline $\mathrm{R}$ & 4 & 4 & 4 & \multirow{4}{*}{ Profil } \\
\hline $\mathrm{O}$ & 5 & 4 & 4 & \\
\hline $\mathrm{J}$ & 3 & 3 & 3 & \\
\hline $\mathrm{H}$ & 4 & 3 & 3 & \\
\hline PREFERENSI & 3 & 5 & 5 & \\
\hline $\mathrm{R}$ & 4,5 & 4 & 4 & \multirow{4}{*}{ GAP } \\
\hline 0 & 3,5 & 4 & 4 & \\
\hline $\mathrm{J}$ & 5 & 3 & 3 & \\
\hline $\mathrm{H}$ & 4,5 & 3 & 3 & \\
\hline
\end{tabular}

\section{Pengelompokan core factor dan secondary factor}

Setelah menentukan nilai pada setiap kriteria hasil Core Factor dan Secondary Factor dapat dilihat di Tabel 17 sampai dengan Tabel 20. Perhitungan core factor dan secondary factor menggunakan rumus (2) dan (3) diatas.

Administrasi memiliki core factor (IPK dan NilaiKuliah). Pada preferensi dengan KodeNama R, Nilai gap untuk IPK dan Nilai kuliah adalah 4,5 dan 4,5 maka untuk menghitung core factornya dengan mencari rata-rata yaitu $(4,5+4,5) / 2=4,5$. Nilai $\mathrm{N}$ merupakan hasil rata-rata dari core factor dan secondary factor. 
TELEMATIKA Vol. 16, No. 1, APRIL, $2019: 1$ - 10

Tabel 17. CF dan SF Administrasi

\begin{tabular}{|c|c|c|c|}
\hline KodeNama & Core & Secondary & $\mathrm{N} 1$ \\
\hline $\mathrm{R}$ & 5,0 & 5 & 5,0 \\
\hline $\mathrm{O}$ & 3,8 & 3 & 3,4 \\
\hline $\mathrm{J}$ & 4,8 & 5 & 4,9 \\
\hline $\mathrm{H}$ & 3,8 & 3 & 3,4 \\
\hline
\end{tabular}

Tabel 18. CF dan SF Kompetensi

\begin{tabular}{|c|c|c|}
\hline KodeNama & Core & N2 \\
\hline $\mathrm{R}$ & 5 & 5 \\
\hline $\mathrm{O}$ & 5 & 5 \\
\hline $\mathrm{J}$ & 5 & 5 \\
\hline $\mathrm{H}$ & 3 & 3 \\
\hline
\end{tabular}

Tabel 19. CF dan SF Microtecahing

\begin{tabular}{|c|c|c|c|}
\hline KodeNama & Core & Secondary & N3 \\
\hline R & 4,7 & 3,5 & 4,1 \\
\hline O & 3,3 & 3,5 & 3,4 \\
\hline J & 4,0 & 3,0 & 3,5 \\
\hline H & 4,0 & 4,5 & 4,3 \\
\hline
\end{tabular}

Tabel 20. CF dan SF Wawancara

\begin{tabular}{|c|c|c|c|}
\hline KodeNama & Core & Secondary & N4 \\
\hline $\mathrm{R}$ & 4,0 & 4,5 & 4,3 \\
\hline $\mathrm{O}$ & 4,0 & 3,5 & 3,8 \\
\hline $\mathrm{J}$ & 3,0 & 5,0 & 4,0 \\
\hline $\mathrm{H}$ & 3,0 & 4,5 & 3,8 \\
\hline
\end{tabular}

\section{Penentuan Ranking}

Hasil akhir dari perhitungan profile matching adalah menentukan ranking dengan menghitung hasil dari N1 sampai dengan N4 yang merupakan hasil dari perhitungan core factor dan secondary factor. Hasil dari penjumlahan N1 sampai dengan N4 dapat dilihat di Tabel 21. Nilaipada kolom Hasil yang bernilai paling besar menunjukan nilai paling baik.

Tabel 21. Penentuan Ranking

\begin{tabular}{|c|c|c|c|r|r|}
\hline KodeNama & N1 & N2 & N3 & N4 & Hasil \\
\hline R & 5,0 & 5,0 & 4,1 & 4,3 & 4,6 \\
\hline O & 3,4 & 5,0 & 3,4 & 3,8 & 3,9 \\
\hline J & 4,9 & 5,0 & 3,5 & 4,0 & 4,3 \\
\hline H & 3,4 & 3,0 & 4,3 & 3,8 & 3,6 \\
\hline
\end{tabular}




\section{KESIMPULAN}

Berdasarkan hasil analisis dan perancangan, bisa ditarik kesimpulan :

1. Profile matching bisa mendapatkan hasil yang lebih akurat dibandingkan dengan melakukan penilaian dan perhitungan secara manual, karena dalam perhitungan profile matching di petakan mana saja yang menjadi kriteria utama yang harus dipenuhi calon asisten.

2. Pengambilan keputusan dengan menggunakan profile matching ini hanya untuk mendukung keputusan reviewer dalam menentukan calon asisten yang lolos. Cara ini bisa dijadikan acuan ataupun tidak tergantung dari keputusan reviewer.

\section{DAFTAR PUSTAKA}

Andri, A.T.S. 2017. Penerapan Metode Profile Matching pada Sistem Pendukung Keputusan Pemilihan Ketua Program Studi (STUDI Kasus: Program Studi Teknik Informatika STMIK Musi Rawas). JUITA. p-ISSN: 2086-9398; e-ISSN: 2579-8901; Volume V, Nomor 2, November 2017.

Baty, W.S. 2015. Perbandingan Metode Profile Matching Dan Simple Additive Weighting Pada Penentuan Jurusan Siswa Kelas X Sman 2 Ngaglik. Jurnal IImiah DASI Vol. 16 No. 1 Maret 2015, pp. 16-22.

Fadlil, A., Prabuwono, A.S., Yudhana, A., Prianto, Eko., 2016. Analisis Perancangan Aplikasi Informasi Administrasi Kepegawaian Dan Kegiatan Berbasis Android, Prosiding SNST ke-7 Magister Teknik Informatika UAD, Pp. 1-6 A6.

Hasif. 2017. Android Unik, Pengertian Metode Prototype, Tahapan Dan Kelebihan Metode Prototype. https://androidunik.com diakses 11 Maret 2019.

Kusrini. 2007. Konsep dan Aplikasi Sistem Pendukung Keputusan. Yogyakarta : Penerbit Andi.

Nurajizah, S. 2015. Sistem Informasi Perpustakaan Berbasis Web Dengan Metode Prototype: Studi Kasus Sekolah Islam Gema Nurani Bekasi. Seminar Nasional Inovasi dan Tren (SNIT), pp. A-214-A-219.

Pratiwi, Henry., 2014, Sistem Pendukung Keputusan Penentuan Karyawan Berprestasi Menggunakan Metode Multi Factor Evaluation Process, Jurnal Sistem Informasi, Volume.5, No.2, Halaman 95-101.

Setiawan, A., Sutardi, Tajidun, LM., 2017. Spk Penilaian Dan Pemberian Bonus Salesman Pada Pt Matakar Kendari Dengan Menggunakan Metode Profile Matching, semanTIK, Vol.3, No.1, Jan-Jun 2017, pp. 199-208, ISSN: 2502-8928 (Online) .

Umar, Rusidy., Fadlil, Abdul., Yuminah., 2018, Sistem Pendukung Keputusan dengan Metode AHP untuk Penilaian Kompetensi Soft Skill Karyawan, Jurnal Ilmu Komputer dan Informatika, Volume.4, No.1, Halaman 27-34. 